\title{
Elevated GDF-15 contributes to pulmonary inflammation upon cigarette smoke exposure
}

\author{
FM Verhamme ${ }^{1}$, LJM Seys ${ }^{1}$, EG De Smet ${ }^{1}$, Provoost $^{1}$, W Janssens ${ }^{2}$, D Elewaut ${ }^{3}$, GF Joos ${ }^{1}$, GG Brusselle ${ }^{1}$ \\ and KR Bracke ${ }^{1}$
}

The molecular mechanisms underlying the pathogenesis of chronic obstructive pulmonary disease (COPD) are still unclear, however signaling pathways associated with lung development, such as the transforming growth factor (TGF)- $\beta$ superfamily, could be implicated in COPD. Growth differentiation factor (GDF)-15, a member of the TGF- $\beta$ superfamily, is involved in inflammation, mucus secretion, and cachexia. We analyzed the pulmonary expression of GDF-15 in smokers and patients with COPD, in cigarette smoke (CS)-exposed cultures of primary human bronchial epithelial cells (pHBECs), and in CS-exposed mice. Next, we exposed GDF-15 KO and control mice to air or CS and evaluated pulmonary inflammation. GDF-15 levels were higher in sputum supernatant and lung tissue of patients with COPD and smokers without COPD compared with never smokers. Immunohistochemistry revealed GDF-15 staining in the airway epithelium. Increased expression and secretion of GDF-15 was confirmed in vitro in CS-exposed pHBECs compared with air-exposed pHBECs. Similarly, GDF-15 levels were increased in lungs of CS-exposed mice. Importantly, GDF-15 deficiency attenuated the CS-induced pulmonary inflammation. These results suggest that increased GDF-15-as observed in lungs of smokers and patients with COPD—contributes to CS-induced pulmonary inflammation.

\section{INTRODUCTION}

Chronic obstructive pulmonary disease (COPD) is characterized by an abnormal inflammatory reaction of the airways and lung parenchyma to cigarette smoke (CS), resulting in destruction of lung parenchyma (=emphysema) and structural changes in and around the airways. Besides smoking cessation, therapies or drugs that slow down the accelerated decline in lung function in patients with COPD are still lacking. ${ }^{1}$ Therefore, it is essential to unravel the mechanistic processes that underlie the inflammatory reaction and subsequent structural changes in COPD.

Members of the transforming growth factor (TGF)- $\beta$ family of proteins, which include TGF- $\beta$ s, activins, bone morphogenetic proteins and growth differentiation factors (GDFs) are crucial for fundamental physiological processes, such as cell growth and differentiation. Dysregulation of these pathways is associated with cancer and developmental disorders. ${ }^{2}$ The GDF proteins form a heterogeneous subfamily of the TGF- $\beta$ superfamily. GDF-15 is one of the most divergent members showing the lowest sequence conservation of all members of the TGF- $\beta$ superfamily. ${ }^{3}$ The receptors and downstream signaling pathways for GDF-15 are still not completely identified, although the use of the canonical TGF- $\beta$ receptors and intracellular SMAD proteins has been suggested. ${ }^{4}$

GDF-15 has originally been identified as an autocrine regulator of macrophage activation, hence its alternative name macrophage inhibitory cytokine 1 . However, it is now clear that GDF-15 is a pleiotropic protein and is expressed in virtually all tissues, pointing toward basic physiological, yet not fully clarified functions. ${ }^{5-7}$ Interestingly, expression of GDF-15 increases markedly upon injury, inflammation, and cancer. ${ }^{8-10}$

As a consequence, GDF-15 serum levels are a reliable predictor of disease progression in a number of inflammatory and malignant diseases such as pancreatic cancer, rheumatoid arthritis and acute coronary syndrome. ${ }^{11-13}$ Moreover, elevated serum levels have been correlated with inflammatory

${ }^{1}$ Laboratory for Translational Research in Obstructive Pulmonary Diseases, Department of Respiratory Medicine, Ghent University Hospital, Ghent, Belgium. ${ }^{2}$ Respiratory Medicine, University Hospital Leuven, Department of Clinical and Experimental Medicine, KU Leuven, Belgium and ${ }^{3}$ Unit for Molecular Immunology and Inflammation, Inflammation Research Center VIB Ghent University and Department of Rheumatology, Ghent University Hospital, Ghent, Belgium. Correspondence: FM Verhamme (fien.verhamme@UGent.be) 
biomarkers, suggesting a link between GDF-15 and inflammation. Similar to the other TGF- $\beta$ superfamily members, GDF- 15 can be both pro- or anti-inflammatory depending on the context, organ, and timing. ${ }^{14,15}$ Interestingly, tumor-associated anorexia and weight loss are mediated by GDF-15. ${ }^{4}$ In patients with COPD, weight loss is an unfavorable prognostic marker as evidenced in the BODE (Body-mass index, Obstruction, Dyspnea, and Exercise capacity) index. ${ }^{16}$ Recently, increased serum levels of GDF-15 have been shown in patients with COPD under stable conditions and during acute exacerbations. ${ }^{17-19}$

In this study, we explored the potential role of GDF-15 in CS-induced inflammation and COPD. We first analyzed the expression of GDF-15 in the airways and lungs of patients with COPD, in CS-exposed cultures of primary human bronchial epithelial cell cultures (pHBECs) and in lungs of CS-exposed mice. Next, we investigated whether deficiency of GDF-15 alters the inflammatory responses in vivo in a mouse model of COPD.

\section{RESULTS \\ GDF-15 levels in the airways and lungs of patients with COPD}

The expression of GDF-15 was analyzed in two independent patient cohorts. In a first cohort of 99 subjects, we analyzed GDF$15 \mathrm{mRNA}$ and protein levels in lung tissue. We extracted mRNA from lung tissue of 18 never smokers, 26 smokers without airflow limitation, 34 patients with COPD GOLD II, and 14 patients with COPD GOLD III-IV (Table 1). We observed higher mRNA expression of GDF-15 in lung tissue of smokers with and without COPD, compared with never smokers (Figure 1a). Importantly, the GDF-15 mRNA levels significantly correlate with lung function parameters of airway obstruction such as $\mathrm{FEV}_{1}$ and forced expiratory volume in $1 \mathrm{~s} /$ forced vital capacity $\left(\mathrm{FEV}_{1} / \mathrm{FVC}\right)$ (Figure $\mathbf{1 b}$ and $\mathbf{c}$ ) as well as with the diffusing capacity of the lung: DLCO (carbon monoxide diffusing capacity) and KCO (DLCO/alveolar volume) (Figure 1d and e). GDF-15 protein levels were measured in lung tissue lysates of 9 never smokers, 8 smokers without airflow limitation, 14 patients with COPD
GOLD II, and 14 patients with COPD GOLD III-IV (Table 2). Similar to the transcript levels, GDF-15 protein levels were increased in lung tissue of smokers with and without COPD in comparison with never smokers (Figure 2a). We found a significant inverse correlation between GDF-15 protein levels and $F E V_{1}$ and $F E V_{1} / F V C$ values (Figure $2 \mathbf{b}$ and $\mathbf{c}$ ), but not with DLCO and KCO (Supplementary Figure S1 online). Linear regression analysis showed that COPD was associated with increased mRNA and protein GDF-15 levels in lung tissue even after adjustment for covariates including smoking status, age, BMI, gender, and use of inhaled corticosteroids (Supplementary Table S1 for mRNA expression and Supplementary Table S2 for protein expression).

In a second independent study population of 41 subjects, supernatant of induced sputum of 7 never smokers, 16 smokers without airflow limitation, and 18 patients with COPD GOLD I-II was analyzed for GDF-15 protein levels (Table 3). Accordingly, protein levels of GDF-15 were significantly elevated in induced sputum of smokers and patients with COPD, compared with never smokers (Figure 2d). We could not demonstrate a significant correlation between GDF-15 protein levels and $\mathrm{FEV}_{1}$ and $\mathrm{FEV}_{1} / \mathrm{FVC}$ (Supplementary Figure S2). Importantly, COPD status was independently associated with GDF-15 levels in induced sputum, as demonstrated by linear regression analysis adjusting for different confounders (Supplementary Table S3).

\section{Human airway epithelial cells express and secrete GDF-15} As airway epithelial cells are reported to be a potential source of GDF-15 in the lungs, we investigated the effect of CS exposure in in vitro cultures of pHBECs. For this purpose, pHBECs were allowed to differentiate under air-liquid conditions, after which they were exposed to mainstream CS. RT-PCR analysis on mRNA extracted from $\mathrm{pHBECs}$ revealed an increased expression of GDF-15 3, 6, and 24h after CS exposure, compared with air-exposed control cells (Figure 3a). This was accompanied by a significantly increased secretion of GDF-15 protein in the basal medium from CS-exposed pHBECs $24 \mathrm{~h}$ after the

Table 1 Characteristics of study subjects for lung mRNA analysis (by qRT-PCR) $(n=92)$

\begin{tabular}{|c|c|c|c|c|}
\hline & Never smokers & Smokers without COPD & COPD GOLD II & COPD GOLD III-IV \\
\hline Gender ratio (m/f) & $6 / 12^{\#}$ & $19 / 7^{\#}$ & $31 / 3^{\#}$ & $8 / 6^{\#}$ \\
\hline Current-/ex-smoker & NA & $16 / 10$ & $22 / 12$ & $0 / 14$ \\
\hline Smoking history (PY) & NA & $28(15-45)^{\star}$ & $45(40-60)^{\star, \S}$ & $30(25-30)^{*, \dagger}$ \\
\hline $\mathrm{FEV}_{1}$ post (\% predicted) & $102(92-116)$ & $95(93-112)$ & $68(61-75)^{\star, \S}$ & $26(20-32)^{\star, \S, \dagger}$ \\
\hline $\mathrm{FEV}_{1} / \mathrm{FVC}$ post (\%) & $78(75-83)$ & $75(71-79)^{\star}$ & $56(53-60)^{\star, \S}$ & $32(27-35)^{*, \S, \dagger}$ \\
\hline ICS (yes/no) & $0 / 18^{\#}$ & $1 / 25^{\#}$ & $15 / 19^{\#}$ & $13 / 1^{\#}$ \\
\hline
\end{tabular}

Abbreviations: f, female; FEV 1 , forced expiratory volume in 1 s; FVC, forced vital capacity; ICS, inhaled corticosteroids; M, male; NA, not applicable; PY, pack years Data are presented as median (IQR).

Mann-Whitney $U$-test: ${ }^{\star} P<0.05$ versus never smokers; ${ }^{\S} P<0.05$ versus smokers without COPD; ${ }^{\dagger} P<0.05$ versus COPD GOLD II.

Fisher's exact test: ${ }^{\#} P<0.001$. 

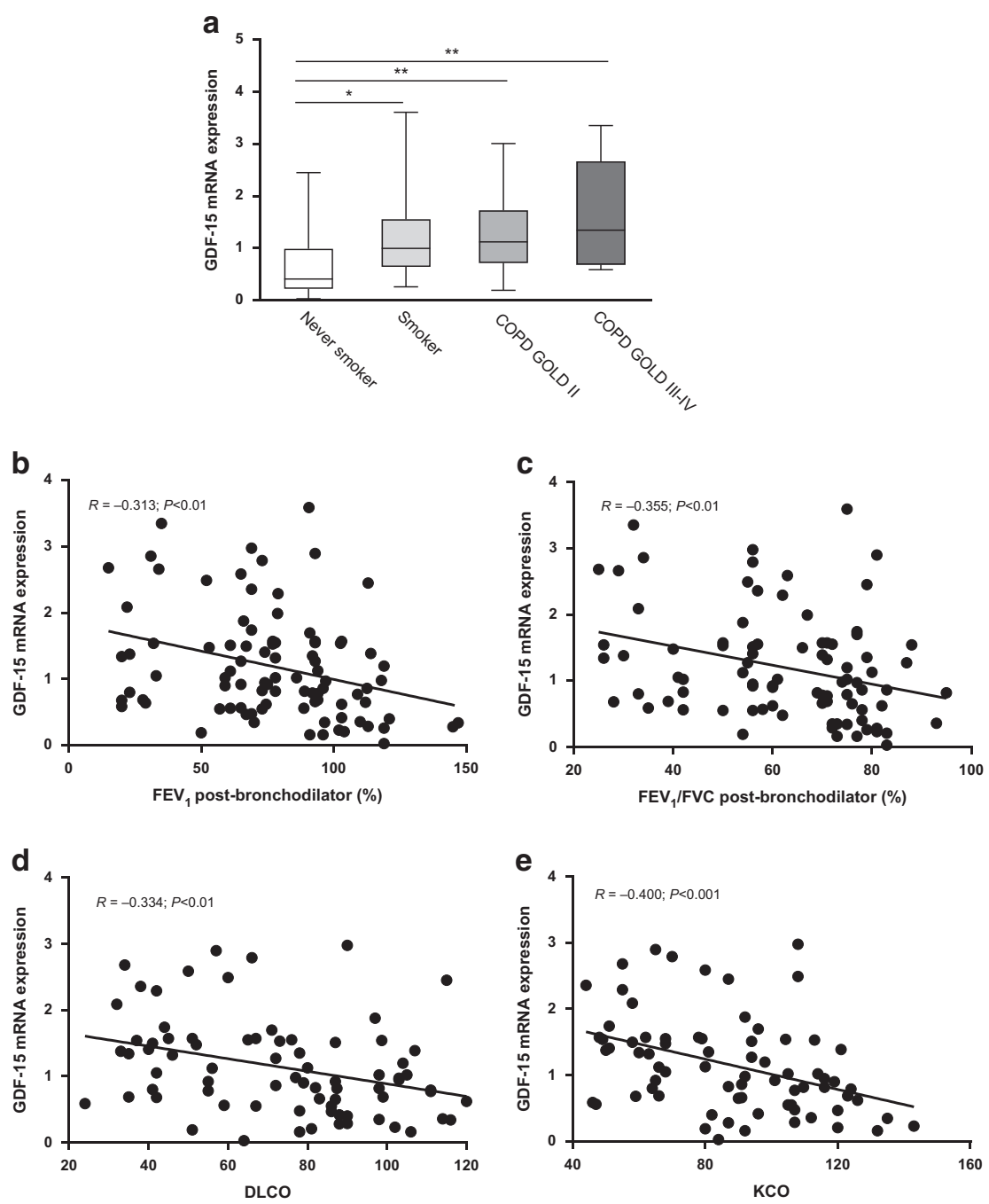

Figure 1 Pulmonary mRNA expression of GDF-15 in human subjects. (a) mRNA levels of GDF-15 in lung tissue of never smokers $(N=18)$, smokers without airflow limitation $(N=26)$, patients with COPD GOLD II $(N=34)$, and patients with COPD GOLD III-IV $(N=14)$, as measured by qRT-PCR. mRNA levels were corrected using a calculated normalization factor based on mRNA expression of three reference genes (GAPDH, PPIA, HPRT-1). Data are expressed as box and whisker plots. For statistical analysis, Kruskal-Wallis followed by Mann-Whitney U-test was used $\left({ }^{*} P<0.05\right.$ and $\left.{ }^{* *} P<0.01\right)$. Parametric correlation analysis (Pearson) of the GDF-15 mRNA levels with lung function parameters such as post-bronchodilator values of forced expiratory volume in $1 \mathrm{~s}\left(\mathrm{FEV} \mathrm{V}_{1}\right)(\mathrm{b})$ and ratio of $\mathrm{FEV}_{1}$ to forced vital capacity $\left(\mathrm{FEV}_{1} / \mathrm{FVC}\right)(\mathbf{c})$, carbon monoxide diffusing capacity (DLCO) (d), and DLCO/alveolar volume (KCO) (e).

exposure (Figure 3b). Immunofluorescent staining for GDF-15 on human lung tissue confirms a positive staining for GDF-15 in airway epithelial cells of patients with COPD (Figure 3c), as also demonstrated by merged images of GDF-15 and E-cadherin double staining (Figure 3d). To investigate which epithelial cells do express GDF-15 protein, we combined GDF-15 with the basal cell marker p63. We observed some GDF-15 positive cells, which stained positive for p63. However, we observed also GDF- $15^{+}$p63 ${ }^{-}$epithelial cells in apically located regions of the airway epithelium, indicating that other cell types (club, ciliated, or goblet cells) produce GDF-15. (Figure 3e).

\section{GDF-15 levels in the airways and lungs of cigarette smoke-exposed mice}

In a next approach, GDF-15 expression was measured in a mouse model of COPD. RNA expression was significantly elevated in lung tissue of mice exposed to CS for 4 weeks (sub-acute exposure) and 24 weeks (chronic exposure) (Figure 4a). Accordingly, both 4 and 24 weeks of CS exposure increased GDF-15 protein levels in lung tissue and bronchoalveolar lavage (BAL) supernatant of mice (Figure $\mathbf{4 b}$ and c). As GDF-15 was originally found to be expressed in activated macrophages, we investigated the mRNA expression of GDF-15 in macrophages isolated from lung tissue and BAL of air- and CS-exposed mice by flow cytometric cell sorting. Interestingly, the GDF-15 expression was higher in sorted alveolar and pulmonary macrophages isolated from CSexposed mice, compared with those of air-exposed control mice (Supplementary Figure S3).

\section{Effect of GDF-15 deficiency on cigarette smoke-induced airway inflammation}

To elucidate the functional role of GDF-15 in CS-induced inflammation, we exposed GDF-15 KO mice and control WT 
Table 2 Characteristics of study subjects for lung protein analysis (by ELISA) $(n=45)$

\begin{tabular}{|c|c|c|c|c|}
\hline & Never smokers & Smokers without COPD & COPD GOLD II & COPD GOLD III-IV \\
\hline Gender ratio (m/f) & $2 / 7^{\circ}$ & $7 / 1^{\circ}$ & $13 / 1^{\circ}$ & $8 / 6^{\circ}$ \\
\hline Current-/ex-smoker & NA & $7 / 1$ & $13 / 1$ & $0 / 14$ \\
\hline Smoking history (PY) & NA & $34(19-52)^{\wedge}$ & $43(40-58)^{\wedge}$ & $30(25-30)^{\wedge}$ \\
\hline $\mathrm{FEV}_{1}$ post (\% predicted) & $112(96-119)$ & $93(79-117)$ & $73(65-77)^{\wedge, ¥}$ & $26(20-32)^{\wedge, 0, \emptyset}$ \\
\hline $\mathrm{FEV}_{1} / \mathrm{FVC}$ post (\%) & $80(77-90)$ & $76(74-78)$ & $56(44-60)^{\wedge, a}$ & $32(27-35)^{\wedge, a, \oplus}$ \\
\hline ICS (yes/no) & $0 / 9^{\#}$ & $1 / 7^{\#}$ & $8 / 6^{\#}$ & $13 / 1^{\#}$ \\
\hline
\end{tabular}

Abbreviations: f, female; FEV , forced expiratory volume in $1 \mathrm{~s}$; ELISA, enzyme-linked immunosorbent assay; FVC, forced vital capacity; ICS, inhaled corticosteroids; M, male; NA, not applicable; PY, pack years.

Data are presented as median (IQR)

Mann-Whitney $U$-test: ${ }^{*} P<0.05$ versus never smokers; ${ }^{\wedge} P<0.001$ versus never smokers; ${ }^{\S} P<0.05$ versus smokers without COPD; ${ }^{\sharp} P<0.01$ versus smokers without $C O P D$;

${ }^{a} P<0.001$ versus smokers without COPD; ${ }^{\dagger} P<0.05$ versus COPD GOLD $\|$; ${ }^{\natural} P<0.001$ versus COPD GOLD II.

Fisher's exact test: ${ }^{\circ} P<0.01 ;{ }^{\#} P<0.001$.

mice (littermates) to CS for 4 weeks. Exposure to CS resulted in increased numbers of macrophages, neutrophils, dendritic cells (DCs), B, and T lymphocytes in the BAL fluid (Figure 5). GDF-15 deficiency had no significant impact on the number of total BAL cells and innate inflammatory cells such as macrophages and neutrophils, whereas DCs, especially the $\mathrm{CD}_{11 \mathrm{~b}^{+}}$subset tended to decrease upon CS exposure (Figure 5a-f). In contrast, we discovered an attenuation of the CS-induced increase in B and T lymphocytes in GDF-15 KO mice compared with WT mice (Figure $\mathbf{5 g}$ and $\mathbf{h}$ ). For $\mathrm{T}$ lymphocytes, both the activated $\left(\mathrm{CD} 69^{+}\right) \mathrm{CD} 4^{+}$and $\mathrm{CD} 8^{+} \mathrm{T}$ lymphocytes were reduced in CS-exposed GDF-15 KO mice compared with CS-exposed WT mice (Figure 5i and $\mathbf{j}$ ). The protein levels in BAL supernatant of CXCL9 and BAFF, important for $\mathrm{T}$ and $\mathrm{B}$ lymphocyte homing and survival, were not affected by GDF-15 deficiency (Supplementary Figure S4).

\section{Effect of GDF-15 deficiency on cigarette smoke-induced inflammation in lung tissue}

In lung tissue, GDF-15 KO mice have slightly reduced numbers of total DCs, including the $\mathrm{CD} 11 \mathrm{~b}^{+} \mathrm{DC}$ subset, whereas the $\mathrm{CD}_{103}{ }^{+}$DCs were significantly lower compared with CSexposed WT mice (Figure 6a-c). In addition, GDF-15 KO mice demonstrated an attenuation of the CS-induced increase of $\mathrm{T}$ lymphocytes, especially the activated $\mathrm{CD} 4^{+} \mathrm{T}$ cells (Figure 6d-f). Remarkably, the CS-induced increase in B lymphocytes was completely absent in GDF-15 KO mice compared with WT mice (Figure 6g). Next, we quantified the mRNA expression of the chemokines Ccl5, Cxcl9, Cxcl13, attracting $\mathrm{B}$ and $\mathrm{T}$ lymphocytes, in lung tissue of air- or CS-exposed GDF-15 KO and WT mice. Ccl5 was at baseline higher in air-exposed GDF$15 \mathrm{KO}$ mice compared with WT controls, but overall there was no effect of CS or genotype on the expression of Ccl5, Cxcl9 and Cxcl13. Similarly, no significant differences were found for CXCL9 protein levels in lung tissue. We observed a reduced BAFF mRNA expression in lung tissue of CS-exposed GDF-15
KO mice compared with control mice; however we could not confirm this at protein level (Supplementary Figure S4).

As we discovered that GDF-15 deficiency strongly suppressed the increase of $\mathrm{T}$ and $\mathrm{B}$ lymphocytes (i.e., the adaptive immune system) upon CS exposure, we investigated whether this was owing to a defect in the antigen presentation process. To address this, we quantified the number of CD86 positive DCs, demonstrating that there was no difference in the number of $\mathrm{CD} 86^{+} \mathrm{DCs}$, nor in the $\mathrm{CD} 11 \mathrm{~b}^{+}$or $\mathrm{CD} 103^{+} \mathrm{DC}$ subsets, between GDF-15 KO mice and WT mice (Supplementary Figure S5).

\section{Extrapulmonary effects of cigarette smoke exposure in GDF-15 deficient mice}

CS-exposed mice gained less weight compared with their airexposed controls during the course of the experiment, resulting in a lower body weight at the end of the experiment. No significant differences were observed regarding the body weight between GDF-15 KO and WT mice upon air or CS exposure (Figure 7a and b). CS-exposed WT mice demonstrated significant wasting of subcutaneous adipose tissue compared with air-exposed WT mice. In contrast, the percentage of subcutaneous adipose tissue in GDF-15 KO mice was significantly increased upon CS exposure (Figure 7c). As a result, the percentage of adipose tissue was significantly higher in CS-exposed GDF-15 KO mice, compared with CS-exposed WT mice.

\section{DISCUSSION}

In this manuscript, we demonstrate that GDF-15 levels are significantly increased in lung tissue and induced sputum of smokers and patients with COPD and correlate significantly with airway obstruction and lung diffusion capacity. Moreover, we identify bronchial epithelial cells as an important source of GDF-15 in lung tissue. In a translational approach, we confirm elevated GDF-15 expression in a CS murine model of COPD. Deficiency of GDF-15 in mice attenuated pulmonary 

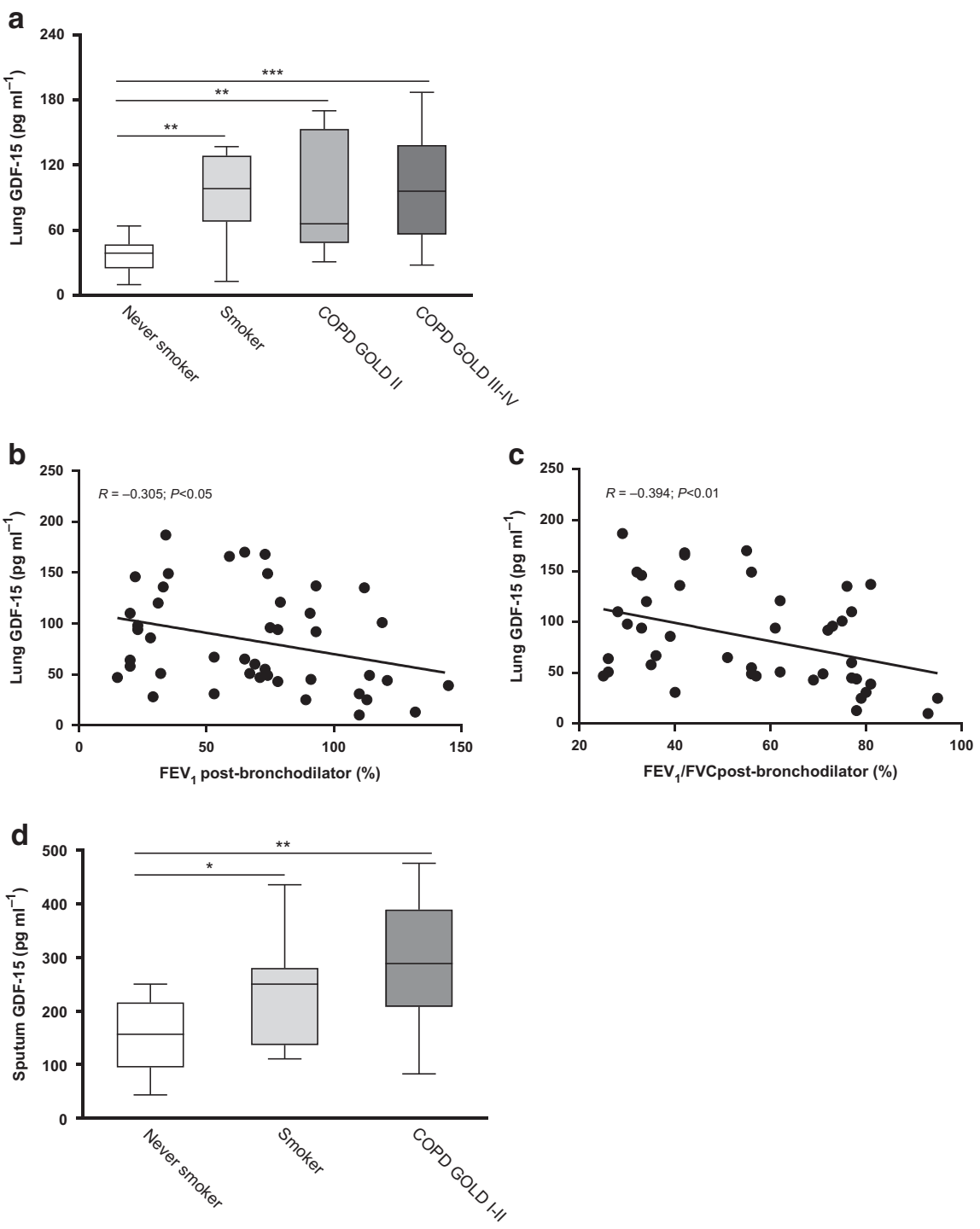

Figure 2 GDF-15 protein levels in lung tissue and induced sputum supernatant of human subjects. (a) Protein levels of GDF-15 in lung tissue of never smokers $(N=9)$, smokers $(N=8)$, patients with COPD GOLD II $(N=14)$, and patients with COPD GOLD III-IV $(N=14)$. Parametric correlation analysis (Pearson) of the GDF-15 protein levels in lung tissue with post-bronchodilator values of forced expiratory volume in $1 \mathrm{~s}\left(\mathrm{FEV} \mathrm{V}_{1}\right)(\mathbf{b})$ and ratio of $\mathrm{FEV} \mathrm{V}_{1}$ to forced vital capacity $\left(\mathrm{FEV}_{1} / \mathrm{FVC}\right)(\mathbf{c})$. (d) Protein levels of GDF-15 in induced sputum supernatant of never smokers $(N=7)$, smokers $(N=16)$, and patients with COPD GOLD I-II $(N=18)$. Protein levels were measured by a commercially available ELISA kit. Data are expressed as box and whisker plots. For statistical analysis, Kruskal-Wallis followed by Mann-Whitney $U$-test was used $\left({ }^{\star} P<0.05,{ }^{\star \star} P<0.01\right.$, and $\left.{ }^{\star \star \star} P<0.001\right)$.

inflammation, especially the increase of lymphocytes, in the airways and lung tissue upon 4 weeks of CS exposure.

We showed higher levels of GDF-15, both at the mRNA and protein level, in lung tissue and supernatants of induced sputum of smokers. The increase in GDF-15 was irrespective of airflow limitation, although the GDF-15 levels tended to be higher in patients with COPD compared with smokers without COPD. Importantly, GDF-15 levels correlated with lung function parameters of airway obstruction and emphysema, suggesting a role of GDF-15 in COPD.

Until now, only circulating GDF-15 levels were reported to be increased in stable COPD and during acute exacerbations of COPD and identified to be an independent predictor of acute exacerbations. ${ }^{17-19}$ Equivalently, GDF-15 is augmented in serum and lung tissue of patients with pulmonary arterial hypertension. ${ }^{20,21}$ Lambrecht et al. $^{22}$ showed that serum GDF-15 levels correlate with the extent of lung fibrosis in patients with systemic sclerosis.

By immunohistochemistry, we observed positive GDF-15 staining in human airway epithelium. In vitro, we confirmed the expression and secretion of GDF-15 in cultures of primary HBECs. Notably, both the expression and secretion into the basal medium of GDF-15 were increased when cells were exposed to mainstream CS. This is in line with recent publications showing increased GDF-15 in airway epithelial cells of smokers and in in vitro CS-exposed pHBECs. These authors also highlighted a role of GDF-15 in mucus overexpression and epithelial senescence, both potentially contributing to the pathogenesis of COPD. ${ }^{23,24}$ 
Table 3 Characteristics of study subjects for sputum analysis (by ELISA) $(n=41)$

\begin{tabular}{|c|c|c|c|}
\hline & Never smokers & Smokers without COPD & COPD GOLD I-II \\
\hline Number & 7 & 16 & 18 \\
\hline Gender ratio (m/f) & $3 / 4^{\circ}$ & $9 / 7^{\circ}$ & $17 / 1^{\circ}$ \\
\hline Age (years) & $55(20-62)$ & $60(51-66)$ & $64(57-72)^{\star}$ \\
\hline Current-/ex-smoker & NA & $6 / 10$ & $4 / 14$ \\
\hline Smoking history (PY) & NA & $30(15-57)^{\wedge}$ & $33(21-73)^{\wedge}$ \\
\hline $\mathrm{FEV}_{1}$ post (L) & $3.1(2.7-3.4)$ & $3.1(2.6-3.7)$ & $2.1(1.9-2.3)^{\wedge, a}$ \\
\hline $\mathrm{FEV}_{1}$ post (\% predicted) & $95(92-101)$ & $106(94-112)$ & $66(58-70)^{\wedge, a}$ \\
\hline $\mathrm{FEV}_{1} / \mathrm{FVC}$ post (\%) & $80(76-93)$ & $79(76-81)$ & $54(46-59)^{\wedge, a}$ \\
\hline ICS (yes/no) & $0 / 9^{\#}$ & $0 / 16^{\#}$ & $10 / 8^{\#}$ \\
\hline \multicolumn{4}{|l|}{ Sputum differential cell count } \\
\hline$\%$ Macrophages & $39(29-50)$ & $36(23-52)$ & $15(10-28)^{*, \S}$ \\
\hline$\%$ Neutrophils & $57(47-69)$ & $60(46-74)$ & $82(65-87)^{\star, \Psi}$ \\
\hline \% Eosinophils & $0.8(0.2-2.5)$ & $0.5(0.3-2.3)$ & $0.8(0.5-3.1)$ \\
\hline \% Lymphocytes & $0.7(0.4-1.3)$ & $0.4(0.0-0.8)$ & $0.2(0.0-0.6)$ \\
\hline \% Bronchial epithelial cells & $0.0(0.0-1.2)$ & $0.2(0.0-0.7)$ & $0.0(0.0-0.2)$ \\
\hline \% Squamous epithelial cells & $2.5(0.9-5.1)$ & $0.7(0.3-1.3)$ & $0.4(0.0-1.9)$ \\
\hline Viability (\%) & $87(69-95)$ & $90(85-94)$ & $92(81-93)$ \\
\hline
\end{tabular}

Abbreviations: f, female; FEV1, forced expiratory volume in 1s; ELISA, enzyme-linked immunosorbent assay; FVC, forced vital capacity; ICS, inhaled corticosteroids; M, male; $\mathrm{NA}$, not applicable; PY, pack years.

Data are presented as median (IQR)

Mann-Whitney $U$-test: ${ }^{*} P<0.05$ versus never smokers; $\wedge P<0.001$ versus never smokers; ${ }^{\S} P<0.05$ versus smokers without COPD; ${ }^{\ddagger} P<0.01$ versus smokers without $C O P D$;

${ }^{a} P<0.001$ versus smokers without COPD.

Fisher's exact test: ${ }^{\circ} P<0.05$; ${ }^{\#} P<0.001$.

Accordingly, we detected significantly higher GDF-15 levels in the lungs and BAL supernatant of CS-exposed mice compared with air-exposed controls both at the sub-acute (4 weeks) and chronic (24 weeks) time points. An upregulation of GDF-15 has also been observed in other animal models of injury in various organs such as lungs, kidney, and liver. ${ }^{8,25}$ Intratracheal bleomycin administration to mice, a commonly used model to mimic lung fibrosis, induces GDF-15 in lung tissue. $^{22}$ In our model, GDF-15 is already increased after 4 weeks of CS and at protein level does not further increase upon longer exposure to CS. Furthermore, we found that the GDF-15 expression is higher in pulmonary and alveolar macrophages of mice exposed to CS compared with macrophages of air-exposed mice.

The combination of our expression data, combined with the evidence from published research, led toward our hypothesis that GDF-15 may participate in the initiation of CS-induced inflammation. First, almost 20 years ago, it has been published that the expression of GDF-15 in macrophages is controlled by various cytokines, such as IL- $1 \beta$ and TNF- $\alpha$, but also that vice versa GDF-15 itself is able to regulate cytokine expression. ${ }^{5}$ Accordingly, GDF-15 is involved in IL-6-independent inflammation in peritoneal macrophages upon vascular injury or in lung fibroblasts upon bleomycin stimulation. ${ }^{22,26}$ Second, GDF-15 is also known to influence inflammatory cell recruitment and migration by affecting chemokine expression, signaling, and integrin activation. ${ }^{14,15}$ Finally, several independent studies established a role of GDF-15 in modulating cell death and apoptosis in various models..$^{14,20,27}$

We showed a significant attenuation of the CS-induced increase in $\mathrm{T}$ and $\mathrm{B}$ lymphocytes in GDF-15 KO mice. In addition, the number of DCs also tended to be lower. Several mechanisms could contribute to this observation. Zhou et al. ${ }^{28}$ demonstrated that GDF- 15 suppresses the maturation of DCs, a process important for lymphocyte activation and recruitment. However, we could not find an effect of GDF-15 deficiency on the number of mature $\mathrm{CD} 86^{+}$DCs. As mentioned before, GDF-15 regulates chemokine expression, nonetheless the expression of known lymphocyte chemokines in our experiments was not affected. Other known functions of GDF-15 such as a direct effect on adhesion and transendothelial migration of lymphocytes or epithelial senescence could account for our results and should be studied further. ${ }^{15,24}$ To our surprise, the number of macrophages in BAL fluid was not different between GDF-15 KO and WT mice. However, this does not rule out a role of GDF-15 in the function of macrophages.

As with all the other members of the TGF- $\beta$ superfamily, GDF-15 has been reported to function both as a pro-or antiinflammatory cytokine. GDF-15 repressed inflammation by acting as an inhibitor of leukocyte integrin activation in a myocardial infarction model in mice. ${ }^{15}$ Accordingly, GDF-15 $\mathrm{KO}$ mice displayed higher expression of inflammatory markers 

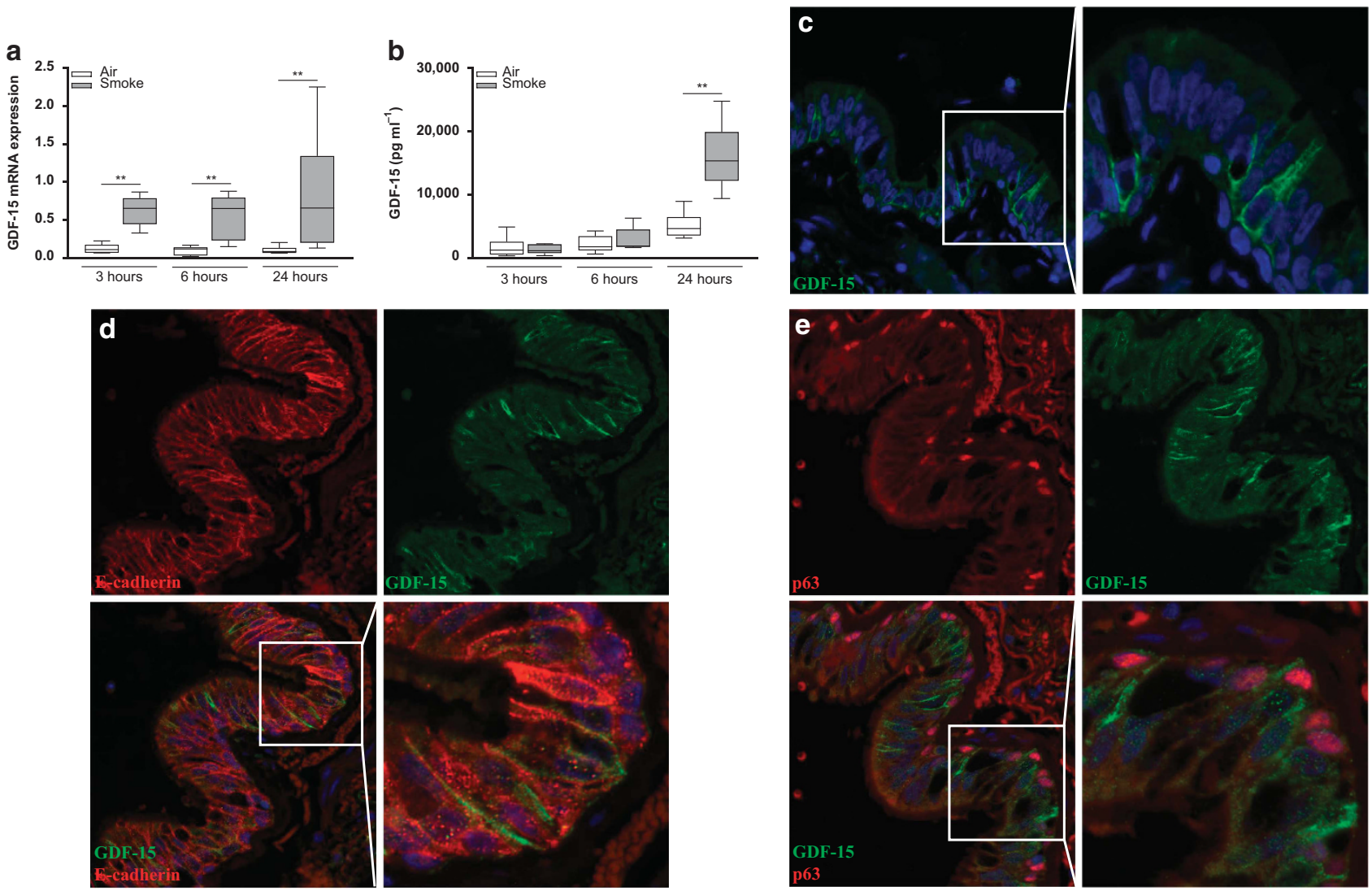

Figure 3 mRNA and protein expression of GDF-15 in human bronchial epithelial cells. (a) mRNA expression of GDF-15 in cultures of primary human bronchial epithelial cells (pHBECs) 3,6, and $24 \mathrm{~h}$ after exposure. mRNA levels were corrected using a calculated normalization factor based on mRNA expression of three reference genes (ATP5B, PPIA, RPL13A). (b) Protein levels of GDF-15 in basal medium of pHBECs 3, 6 and $24 \mathrm{~h}$ after exposure. Data are expressed as box and whisker plots of six different experiments each performed in duplicate and using cells from different donors. For statistical analysis, Mann-Whitney $U$-test was used $\left({ }^{\star *} P<0.01\right)$. (c) Representative photomicrograph of immunofluorescence staining for GDF-15 (green) of lung sections of a patient with COPD (GOLD II). Representative photomicrograph of immunofluorescence double staining for GDF-15 (green) and E-cadherin (red) (d) or GDF-15 (green) and p63 (red) (e) of lung sections of a patient with COPD (GOLD II). Double positive nuclei for p63 and DAPI stain pink. Original magnification $\times 400$.

in a diabetes type 1 model. ${ }^{29}$ In contrast, GDF-15 KO mice are protected against atherosclerosis by attenuation of macrophage chemotaxis. ${ }^{14}$ Our data indicate that GDF-15 promotes pulmonary inflammation after CS in the sub-acute exposure model; nevertheless, the pro-inflammatory function of GDF-15 should be confirmed in a long-term chronic model.

Patients with COPD display not only pulmonary symptoms and pathology, but also extrapulmonary manifestations, such as osteoporosis, cardiovascular diseases, and anorexia/cachexia. ${ }^{30}$ GDF-15 has been identified as an adipokine and central regulator of tumor-induced anorexia and weight loss. ${ }^{4,31}$ In a recent study, the authors presented increased GDF-15 levels in muscle of patients with COPD, which were inversely correlated with exercise capacity. ${ }^{32}$ Therefore, we analyzed body weight and adipose tissue mass in CS-exposed WT and GDF-15 KO mice. Intriguingly, the adipose tissue pads of GDF-15 KO mice were significantly larger compared with those of the WT mice.

One of the strengths of our study is the combination of ex vivo, in vitro, and in vivo experiments, which allowed us to investigate the involvement of GDF-15 in cigarette smokeinduced inflammatory processes. One limitation is the presence of a gender imbalance in our human study population. We have addressed this issue by performing linear regression analysis which indicated that gender was not significantly associated with GDF-15 expression, but that COPD status is a significant determinant, independent of other confounders.

In conclusion, we have shown that CS induces the expression of GDF-15 both ex vivo in human subjects with and without COPD, in vitro in pHBECs and in vivo in a well-established murine model of COPD. Importantly, deficiency of GDF-15 in mice attenuated pulmonary inflammation upon sub-acute CS exposure, implicating GDF-15 as a novel mediator of CSinduced inflammatory processes.

\section{METHODS}

Human study populations. Lung resection specimens were obtained from 99 patients, of which 85 from surgery for solitary pulmonary tumors (Ghent University Hospital, Ghent, Belgium) and 14 from explant lungs of end-stage COPD patients undergoing lung transplantation (University Hospital Gasthuisberg, Leuven, Belgium). Lung tissue of 92 (out of 99) patients, including 18 never smokers, 26 smokers without airflow limitation, 34 patients with COPD GOLD II, and 14 patients with COPD GOLD III-IV was used for mRNA 

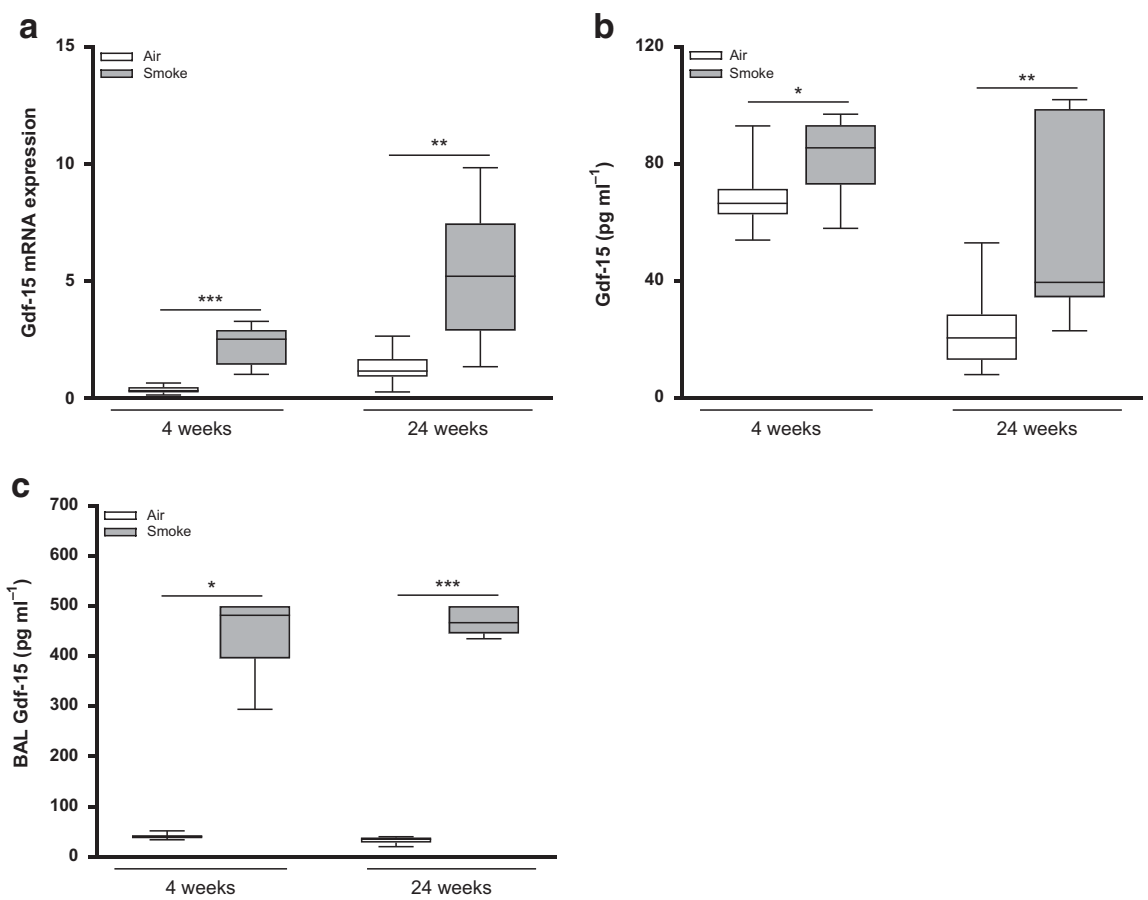

Figure 4 Pulmonary mRNA and protein expression of Gdf-15 in cigarette smoke-exposed C57BL/6 mice. mRNA (a) and protein (b) levels of Gdf-15 in lung tissue of C57BL/6 mice exposed to air or CS for 4 and 24 weeks, as measured by qRT-PCR and ELISA, respectively. mRNA levels were corrected using a calculated normalization factor based on mRNA expression of three reference genes (Gapdh, Tfrc, Hprt-1). (c) Protein levels of Gdf-15 in supernatant of BAL of C57BL/6 mice exposed to air or CS for 4 and 24 weeks, as measured by ELISA ( $N=8-10$ animals per group). Data are expressed as box and whisker plots. For statistical analysis, Mann-Whitney U-test was used $\left({ }^{\star} P<0.05,{ }^{\star \star} P<0.01\right.$, and $\left.{ }^{\star \star \star} P<0.001\right)$.

expression analysis (Table 1). Lung tissue of 45 (out of 99) patients, including 9 never smokers, 8 smokers without airflow limitation, 14 patients with COPD GOLD II and 14 patients with COPD GOLD III-IV was used for protein analysis (Table 2). Lung tissue of 38 (out of 99) patients was used for both mRNA and immunohistochemical analysis. Lung tissue at maximum distance from the pulmonary lesions and without signs of retro-obstructive pneumonia or tumor invasion was collected by a pathologist. None of the patients operated for malignancy were treated with neo-adjuvant chemotherapy. Ex-smokers were at least 1 year abstinent of smoking.

Sputum induction was performed on 41 subjects who were recruited from the outpatient pulmonary clinic of the Ghent University Hospital or by advertising (Table 3). There was no overlap between the subjects of lung tissue and sputum analysis. Sputum induction and processing was performed as described previously. ${ }^{33}$

COPD diagnosis and severity was defined using pre-operative spirometry according to the Global Initiative for Chronic Obstructive Lung Disease (GOLD) classification. ${ }^{1}$ Written informed consent was obtained from all subjects. This study was approved by the medical ethical committees of the Ghent University Hospital (2011/14) and the University Hospital Gasthuisberg Leuven (S51577).

Animals. Male C57Bl/6J GDF-15 heterozygous mice were mated with female C57Bl/6J GDF-15 heterozygous mice in the animal facility at the Faculty of Medicine and Health Sciences, Ghent University (Ghent, Belgium). ${ }^{8}$ Genotyping of the offspring was performed on toe DNA by non-quantitative RT-PCR and gel electrophoresis using the following primers: KO forward (5'-GCTGTCCGGATACTCAGTCCAGAGG$\left.3^{\prime}\right)$, KO reverse (5'-CGCCTTCTTGACGAGTTCTTCTGAGGG-3'), WT forward (5'-CTTGGAGACTGTGCAGGCAACTCTTG- $3^{\prime}$ ) and WT reverse (5'-GTGACACACCACTGTCTGTCCTGTGC-3') to generate 600 and 250 bp products specific for the knockout and wildtype alleles, respectively. From the offspring, male GDF-15 KO mice and their WT littermates were used for the present study. C57BL/6J mice were purchased from the Jackson Laboratory (Bar Harbor, ME, USA). All mice were housed in sterilized cages with filter tops under $12 \mathrm{~h}$ light/dark cycle and ad libitum access to food (Pavan, Brussels, Belgium) and chlorinated tap water. All in vivo manipulations were approved by the local Ethics Committee for animal experimentation of the Faculty of Medicine and Health Sciences, Ghent University.

CS exposure. The mice were exposed to CS, as described previously. ${ }^{34}$ In brief, the animals were exposed whole body to mainstream CS of 5 cigarettes (Reference Cigarette 3R4F without filter; University of Kentucky) four times a day with 30-min smoke-free intervals, for 4 weeks (sub-acute), 12 weeks, or 24 weeks (chronic). The control groups were exposed to room air. An optimal smoke/air ratio of $1 / 6$ was obtained. CS exposure started at an age of 8-9 weeks. Twenty-four hours after the last exposure, mice were killed by an intraperitoneal injection of pentobarbital (CEVA-Sanofi, Paris, France).

BAL. BAL was performed as previously described. ${ }^{35}$ In brief, lungs were first lavaged using $3 \times 300 \mu \mathrm{l}$ HBSS, without $\mathrm{Ca}^{2+}$ and $\mathrm{Mg}^{2+}$ and supplemented with $1 \%$ bovine serum albumin (for protein measurement), followed by $3 \times 1 \mathrm{ml} \mathrm{HBSS}$ without $\mathrm{Ca}^{2+}$ and $\mathrm{Mg}^{2+}$ supplemented with $0.6 \mathrm{~mm}$ ethylenediaminetetraacetic acid, via a tracheal cannula. The lavage fractions were pooled. Total BAL counts were obtained using a Bürker chamber and differential cell counts (on at least 400 cells) were performed on cytocentrifuged preparations after May-Grünwald-Giemsa staining.

Lung harvest and preparation of single-cell suspensions Following BAL, the pulmonary and systemic circulation was rinsed with saline, supplemented with $5 \mathrm{~mm}$ ethylenediaminetetraacetic acid. The left lung was used for histology, as previously described. ${ }^{34}$ The right lung is clamped and removed for RNA extraction (small lobe), preparation of lung homogenates (middle lobe) and preparation of 

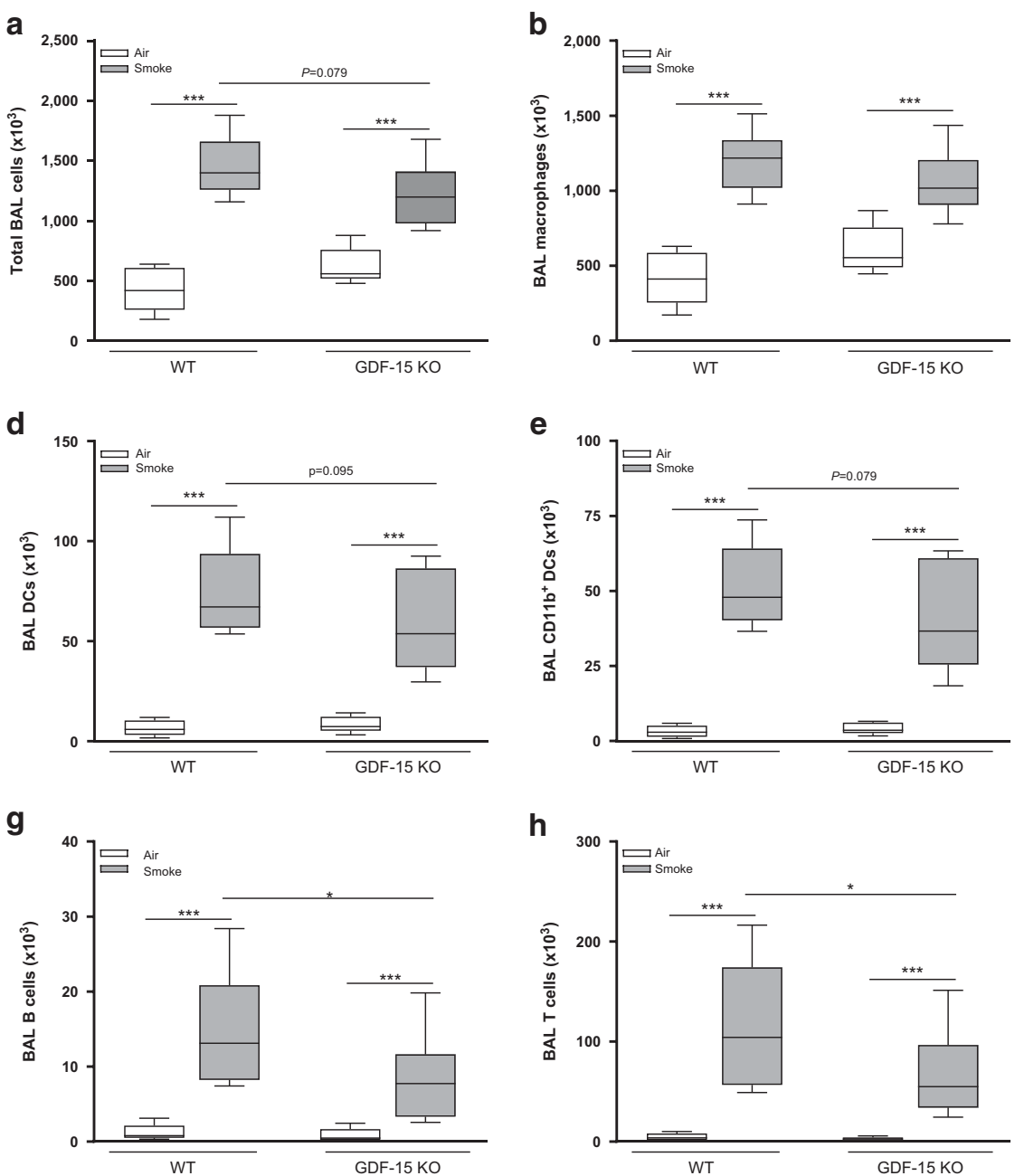

h
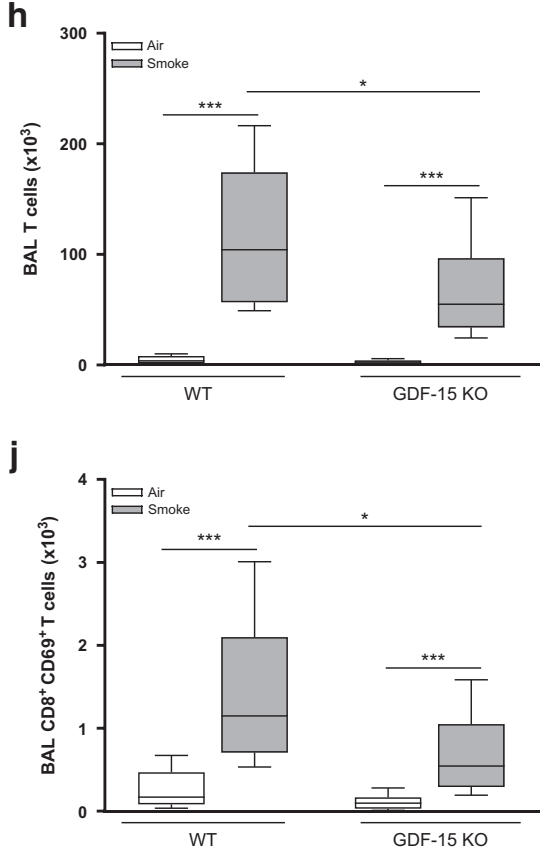
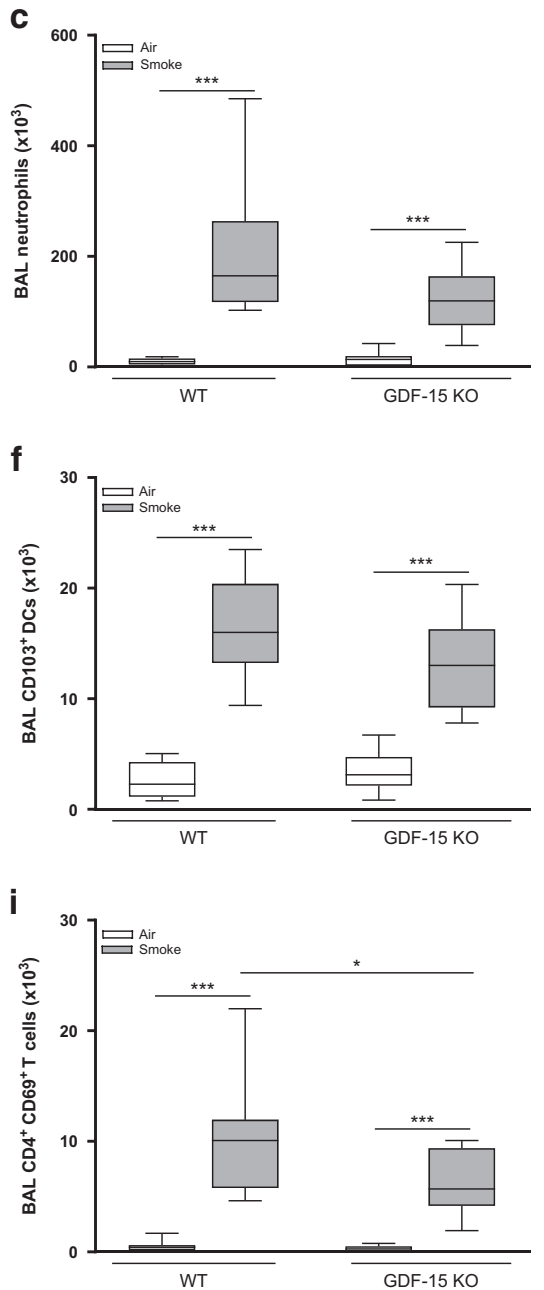

Figure 5 Effect of CS exposure and GDF-15 deficiency on the total number of bronchoalveolar lavage (BAL) cells and cell subsets in BAL fluid. Total BAL cells (a), macrophages (b), neutrophils (c), dendritic cells (DCs) (d), CD11b ${ }^{+}$DCs (e), CD103 ${ }^{+}$DCs (f), B lymphocytes (g), T lymphocytes (h), $\mathrm{CD}^{+}{ }^{+} \mathrm{CD} 9^{+} \mathrm{T}$ lymphocytes (i), and $\mathrm{CD} 8^{+} \mathrm{CD}^{+} 9^{+} \mathrm{T}$ lymphocytes (j) in bronchoalveolar lavage fluid of GDF-15 KO and WT mice upon 4 weeks exposure to air or CS. All cell types were enumerated by flow cytometry, except for the total BAL cells and macrophages which were determined by cytospin counts. Data are expressed as box and whisker plots $(N=8-12$ animals per group). For statistical analysis, Kruskal-Wallis followed by Mann-Whitney $U$-test was used $\left({ }^{\star} P<0.05,{ }^{\star * \star} P<0.001\right)$. Data shown are representative of two independent experiments.

single-cell suspensions (major lobe). In brief, the lung was thoroughly minced, digested, and subjected to red blood cell lyses. After passage through a $50 \mu \mathrm{m}$ cell strainer, cells were counted with a Z2 particle counter (Beckman-Coulter, Inc., Fullerton, CA, USA). ${ }^{34}$

Adipose tissue. The subcutaneous white adipose tissue pads were dissected from air- and CS-exposed GDF-15 WT and KO mice and weighed. The adipose tissue weight was normalized to the total body weight.
Flow cytometry. The cells (both BAL and lung single-cell suspensions) were first incubated with FcR blocking antibody (anti-CD16/CD32, clone 2.4G2) to reduce non-specific binding. Second, labeling reactions were performed to identify the neutrophils, DCs and lymphocytes, using the following Abs: FITC conjugated CD45 (clone 30-F11), phycoerythrin (PE)-conjugated Siglec-F (clone E50-2440), allophycocyanin conjugated CD11c (clone HL3), Alexa Fluor 700 conjugated Ly6C (clone AL -21), phycoerythrin-Cy7-conjugated Ly6G (clone 

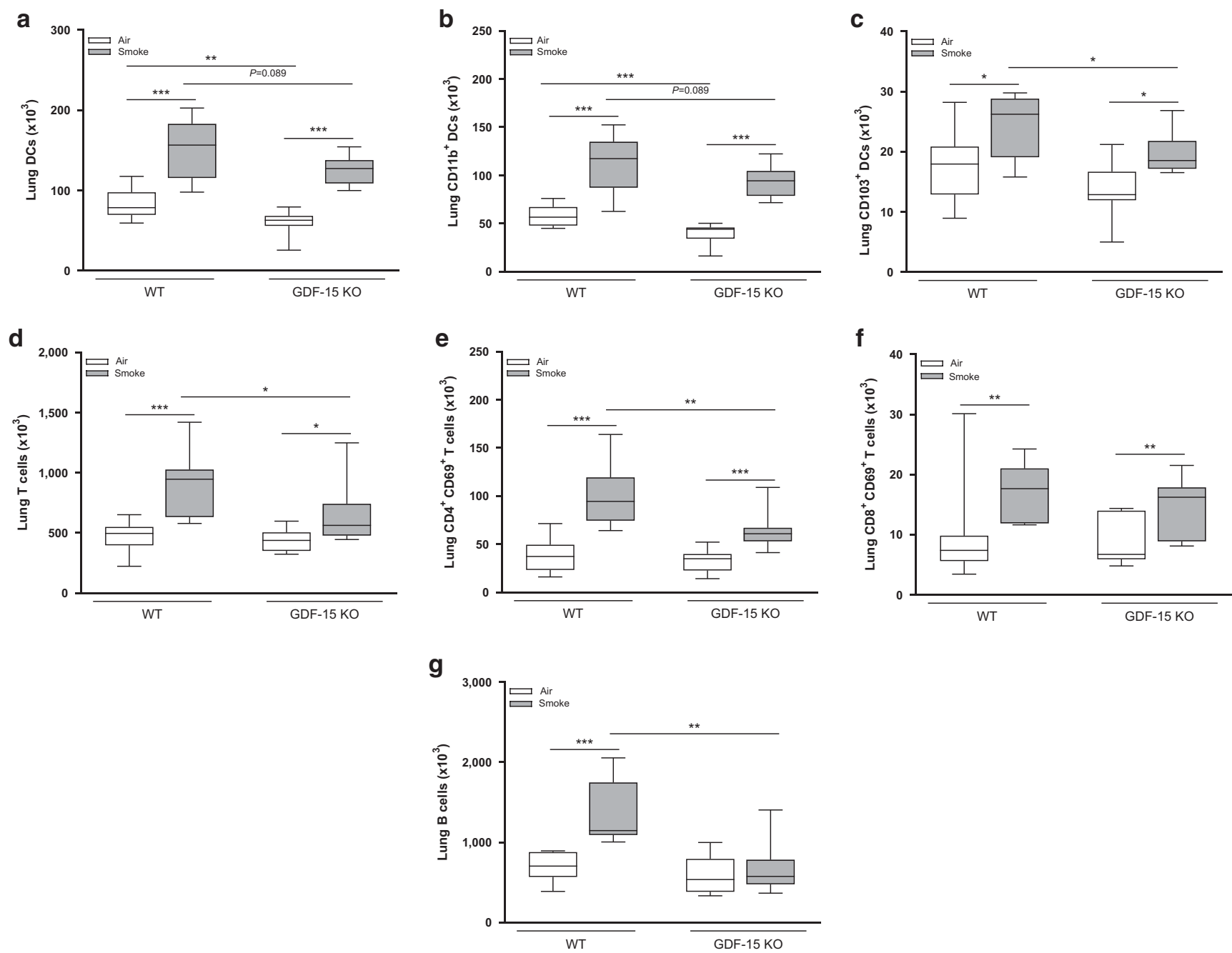

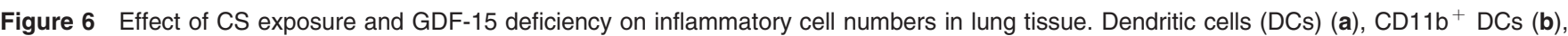
$\mathrm{CD}_{103}{ }^{+} \mathrm{DCs}(\mathbf{c}), \mathrm{T}$ lymphocytes (d), CD4 ${ }^{+} \mathrm{CD} 69^{+} \mathrm{T}$ lymphocytes (e), CD8 ${ }^{+} \mathrm{CD} 69^{+}$T lymphocytes (f), and B lymphocytes (g) in lung tissue of GDF15-deficient and WT mice upon 4 weeks exposure to air or CS. All cell types were enumerated by flow cytometry. Data are expressed as box and whisker plots $\left(N=8-12\right.$ animals per group). For statistical analysis, Kruskal-Wallis followed by Mann-Whitney $U$-test was used $\left({ }^{\star} P<0.05,{ }^{\star \star} P<0.01\right.$, $\left.{ }_{* \star *} P<0.001\right)$. Data shown are representative of two independent experiments.

1A8), phycoerythrin-conjugated CD69 (H1.2F3) and phycoerythrinCy7-conjugated CD24 (clone M1/69) from BD Biosciences (San Diego, CA, USA), Alexa Fluor 700-conjugated CD8 (clone 536.7), Alexa Fluor 700-conjugated CD86 (clone GL-1), allophycocyanin-Cy7-conjugated MHC-II (I-A/I-E, clone M5/114.15.2), BV421-conjugated CD103 (clone 2E7), Pacific Blue-conjugated CD3 (clone 145-2C11) and allophycocyanin-conjugated CD4 (clone GK1.5) from Biolegend (San Diego, CA) and BV605 conjugated CD11b (clone $\mathrm{M} 1 / 70$ ) and efluor 450 conjugated B220 (clone RA3-6B2) from eBioscience (San Diego, CA). All reactions were performed on ice in fluorescence-activated cell sorting -ethylenediaminetetraacetic acid buffer. After excluding doublets, the $\mathrm{CD} 45^{+}$cells were retained. First, alveolar macrophages were gated out as Siglec- $\mathrm{F}^{+}$and $\mathrm{CD} 11 \mathrm{c}^{+}$cells. Of the remaining cell population, the DCs were defined as MHC-II ${ }^{\text {hi }}$ and $\mathrm{CD} 11 \mathrm{c}^{\mathrm{hi}}$ with as subpopulations: $\mathrm{CD} 103^{+} \mathrm{DCs}\left(\mathrm{CD} 103^{+}\right.$and $\left.\mathrm{CD} 11 \mathrm{~b}^{-}\right)$ and $\mathrm{CD}_{11 \mathrm{~b}^{+}}$DCs $\left(\mathrm{CD} 103^{-}\right.$and $\left.\mathrm{CD} 11 \mathrm{~b}^{+}\right)$. CD86 was used as a maturation marker for DCs. After gating out the alveolar macrophages and the DCs, neutrophils were identified as $\mathrm{CD} 11 \mathrm{c}^{-} \mathrm{CD} 11 \mathrm{~b}^{+}$ Ly6G $^{+}$Ly6C $^{\text {int }}$. From the $\mathrm{CD}_{4} 5^{+}$population, B lymphocytes were characterized as small, $\mathrm{CD}^{-}{ }^{-}, \mathrm{B}_{2} 20^{+}, \mathrm{MHC}_{-} \mathrm{II}^{+}$, and Tymphocytes as small, $\mathrm{B}_{22}{ }^{-}, \mathrm{MHC}^{-} \mathrm{II}^{-}, \mathrm{CD}^{+}$, which are further separated in $\mathrm{CD} 4{ }^{+}$ and $\mathrm{CD} 8^{+} \mathrm{T}$ lymphocytes with CD69 as activation marker.
Flow cytometry data acquisition was performed on a LSR Fortessa flow cytometer running FACSDiva software (BD Biosciences). FlowJo Software (Tree Star Inc., Ashland, OR, USA) was used for data analysis.

Separation of lung and BAL macrophages. CD $11 c^{+}$cells from the lung single-cell suspensions were purified following incubation with anti-CD11c microbeads (Miltenyi Biotec, Bergisch Gladbach, Germany) and passage through a VarioMACS magnetic cell separator. Thereafter, lung CD11c + cells and BAL cells were incubated with anti-CD11c. Macrophage populations were sorted on a FACS Vantage with a Sort Enhancement Module as high autofluorescent, $\mathrm{CD}_{11 \mathrm{c}^{+}}$cells, according to the gating strategy detailed by Bracke et al. ${ }^{36}$

Preparation of lung tissue homogenate. The middle lobe of the right lung was snap-frozen (in liquid nitrogen) and stored at $-80^{\circ} \mathrm{C}$ until further analysis. The lobes were transferred to tubes containing $1 \mathrm{ml}$ radioimmunoprecipitation assay buffer (Cell Signaling Technology, Danvers, MA, USA) containing Halt Protease Inhibitor Cocktail Kit (Thermo Scientific, Waltham, MA, USA) and homogenized on ice using TissueRuptor (Qiagen, Hilden, Germany). The homogenates were sonicated ( 4 times for $5 \mathrm{~s}$ ) and centrifuged (14,000 rpm for $10 \mathrm{~min}$ at $4{ }^{\circ} \mathrm{C}$ ) and the middle layer was transferred to microcentrifuge tubes. Total protein concentration was measured using the Pierce BCA 

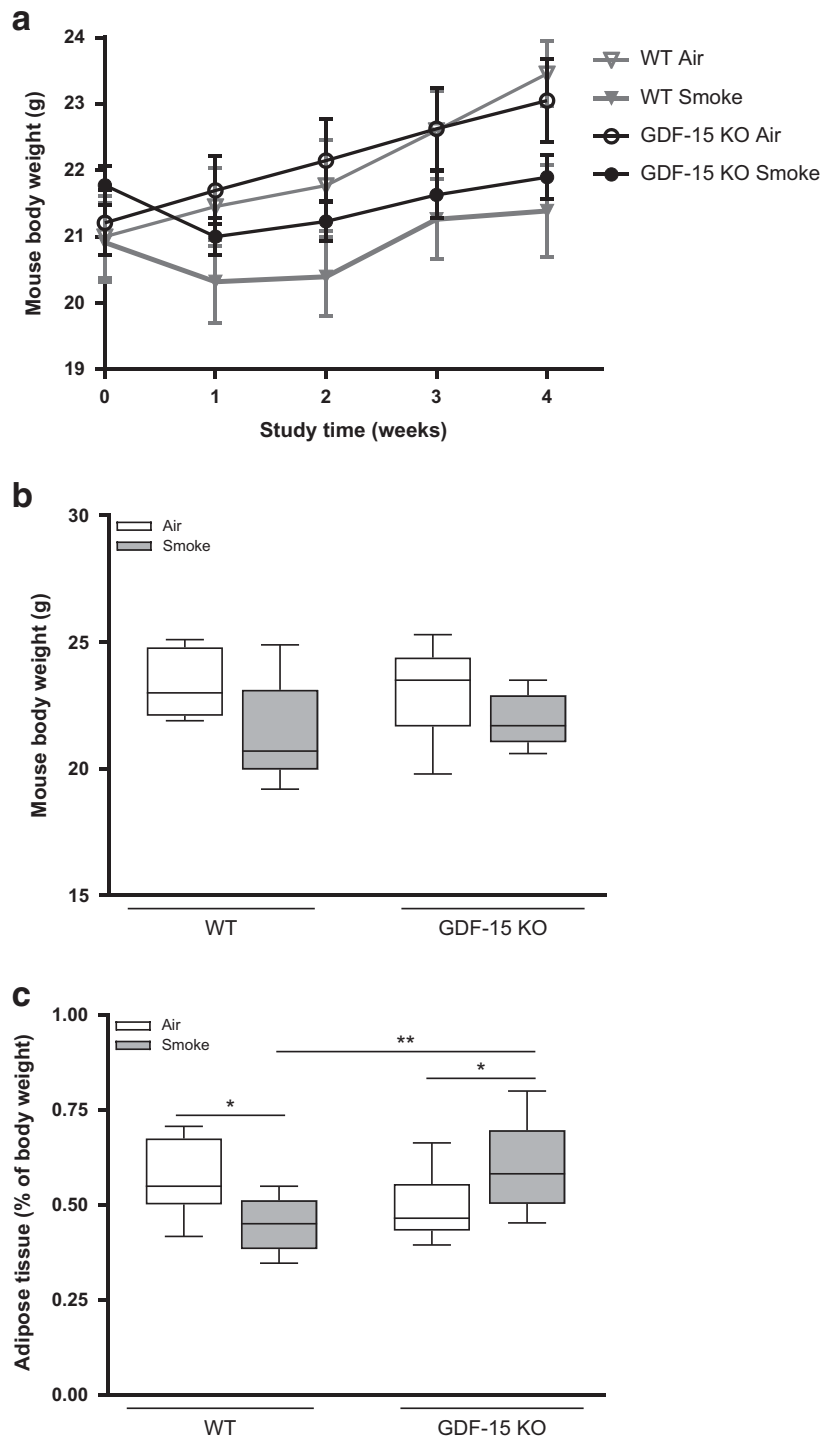

Figure 7 Extrapulmonary effects of CS exposure in GDF-15 KO mice. (a) Body weight changes throughout the 4 weeks of the experiment. Body weight was measured every week. (b) Final body weight at the end of 4 weeks air- or CS exposure. (c) Changes in the weight of subcutaneous adipose tissue of GDF-15 KO and WT mice upon 4 weeks exposure to air or CS. Data are reported relatively to the measured body weight. Data are expressed as box and whisker plots ( $N=8-12$ animals per group). For statistical analysis, Kruskal-Wallis followed by Mann-Whitney U-test was used $\left({ }^{*} P<0.05,{ }^{* \star} P<0.01\right)$. Data shown are representative of two independent experiments.

Protein Assay Kit (Thermo Scientific). Lung tissue homogenates were diluted with radioimmunoprecipitation assay buffer to a final protein concentration of $500 \mu \mathrm{g} \mathrm{ml}^{-1}$.

Exposure of pHBECs to CS. pHBECs were exposed to CS, as described previously. ${ }^{37}$ Basal media were collected for protein analysis and cells were harvested for RNA extraction, 3, 6, and $24 \mathrm{~h}$ after the exposure.

Enzyme-linked immunosorbent assay. We determined GDF-15 protein levels, both human and mice, using a commercially available DuoSet ELISA Development kit (R\&D Systems, Abingdon, UK) with a sensitivity of $7.81 \mathrm{pg} \mathrm{ml}^{-1}$. The protein levels of CXCL9 and BAFF in mouse lung tissue and BAL supernatant were measured by a commercially available ELISA kit from Sigma-Aldrich (St. Louis, MO) (sensitivity of $3 \mathrm{pg} \mathrm{ml}^{-1}$ ) and R\&D Systems (sensitivity of $7.8 \mathrm{pg} \mathrm{ml}^{-1}$ ) respectively. Enzyme-linked immunosorbent assays were performed following the manufacturer's instructions.

Dual immunofluorescence staining. All tissue stainings were performed on $3 \mu \mathrm{m}$ thick paraffin-embedded lung sections, which were cut on poly-L-lysin-coated slides. After dewaxing with Ultra Clear (Klinipath, Duiven, The Netherlands) and rehydrations, antigen retrieval was performed using citrate-buffer. After application of Fc-block, slides were incubated overnight with rabbit polyclonal antiGDF-15 (Abcam), mouse monoclonal anti-p63 (Abcam, Cambridge, $\mathrm{UK})$, mouse monoclonal anti-E-cadherin (BD Biosciences) or isotype rabbit IgG (Abcam), isotype mouse IgG2a (BD Biosciences). Goatanti-rabbit-Alexa488- and donkey-anti-mouse-Alexa586-labeled secondary antibodies (Invitrogen, Merelbeke, Belgium) were incubated overnight together with DAPI (Invitrogen) as nuclear counterstaining. After rinsing with PBS and demineralized water, sections were mounted in Vectashield Hardset (Vector Laboratories, Burlingame, CA, USA). Photomicrographs were taken using Axiovision software (Zeiss, Oberkochen, Germany).

RNA extraction and real-time PCR analysis. RNA was extracted with the miRNeasy Mini kit (Qiagen) from total lung tissue blocks (human and mice) submersed in RNA-later, from pHBECs and from macrophages sorted from BAL and lungs of mice. Complementary DNA was obtained by the Transcriptor First Strand cDNA synthesis kit (Roche, Basel, Switzerland), following manufacturer's instructions. Expression of target genes GDF-15, Ccl5, Cxcl9, Cxcl13, Baff and reference genes Glyceraldehyde-3-phosphate dehydrogenase, Hypoxanthine phosphoribosyltransferase-1, and Peptidylpropyl isomerase 1 were analyzed using Taqman Gene Expression Assays (Applied Biosystems, Forster City, CA, USA). Real-time PCR reactions were set up in duplicate using diluted complementary DNA using identical amplification conditions for each of the target and reference genes. A standard curve derived from serial dilutions of a mixture of all samples were included in each run. The amplification conditions consisted of: $10 \mathrm{~min}$ at $95^{\circ} \mathrm{C}$ and 50 cycles of $95^{\circ} \mathrm{C}$ for $10 \mathrm{~s}$, and $60^{\circ} \mathrm{C}$ for $15 \mathrm{~s}$. Amplifications were performed using a LightCycler 96 detection system (Roche). Data were processed using the standard curve method. Expression of target genes was corrected by a normalization factor that was calculated based on the expression of two or three reference genes, using the geNorm applet according to the guidelines and theoretical framework previously described (http:// medgen.ugent.be/ $\sim$ jvdesomp/genorm/). ${ }^{38}$

Statistical analysis. Statistical analysis was performed with Sigma Stat software (SPSS 19.0, Chicago, IL, USA), using Kruskal-Wallis, MannWhitney $U$, Fisher's exact test and Pearson correlation analysis. Characteristics of the study population are expressed as median and interquartile range. Reported values are expressed as box and whisker plots. Differences at $P$-values $<0.05$ were considered to be significant $\left({ }^{\star} P<0.05,{ }^{* *} P<0.01\right.$ and $\left.{ }^{* *} P<0.001\right)$.

SUPPLEMENTARY MATERIAL is linked to the online version of the paper at http://www.nature.com/mi

\section{ACKNOWLEDGMENTS}

We would like to thank Greet Barbier, Indra De Borle, Katleen De Saedeleer, Anouck Goethals, Marie-Rose Mouton, Ann Neesen, Lien Coulembier, and Evelyn Spruyt from the laboratory for Translational Research in Obstructive Pulmonary Diseases, Department of Respiratory Medicine (Ghent University Hospital, Ghent, Belgium) for their excellent technical assistance. Furthermore, we thank S.J. Lee (Johns Hopkins University) for kindly providing the GDF-15 knockout mice. We also thank Professor Pieter Hiemstra (Department of Pulmonology, Leiden University Medical Centre) for the CS- exposure of cultured HBECs, Professor Bart Vanaudenaerde, and Dr Stijn Verleden (Department of Pneumology, Leuven) for providing us with the explant lungs of patients with severe COPD. The research described in this article was supported by the Concerted Research Action 
of the Ghent University (BOF/GOA, 01G02714), by the Fund for Scientific Research in Flanders (FWO Vlaanderen), and by the Interuniversity Attraction Poles program (IUAP, P7/30). Part of this work was supported by COSTAction BM1201, Developmental Origins of Chronic Lung Disease. $\mathrm{SP}$ is a postdoctoral researcher of the Fund for Scientific ResearchFlanders. DE was supported by grants from the Fund for Scientific Research-Flanders (FWO), the Group-ID Multidisciplinary Research Platform of Ghent University, the Interuniversity Attraction Poles Program (Project P7/07), and the Strategic Basic Research program of the Instituut voor Innovatie door Wetenschap en Technologie (IWT).

\section{AUTHOR CONTRIBUTIONS}

K.R.B., G.G.B. and F.M.V. conceived the project and designed the experiments; K.R.B., F.M.V., L.J.M.S., E.G.D. and S.P. conducted the experiments; K.R.B., G.G.B., F.M.V., G.F.J., L.J.M.S., D.E. and W.J. contributed to the data analysis, plotting, and interpretation; F.M.V. wrote the manuscript and all authors contributed to the writing and editing of the manuscript.

\section{DISCLOSURE}

The authors declared no conflict of interest.

c 2017 Society for Mucosal Immunology

\section{REFERENCES}

1. Vestbo, J. et al. Global strategy for the diagnosis, management, and prevention of chronic obstructive pulmonary disease GOLD executive summary. Am. J. Respir. Crit. Care Med. 187, 347-365 (2013).

2. Massagué, J., Blain, S.W. \& Lo, R.S. TGF $\beta$ signaling in growth control, cancer, and heritable disorders. Cell 103, 295-309 (2000).

3. Böttner, M. et al. Characterization of the rat, mouse, and human genes of growth/differentiation factor-15/macrophage inhibiting cytokine-1 (GDF-15/MIC-1). Gene 237, 105-111 (1999).

4. Johnen, H. et al. Tumor-induced anorexia and weight loss are mediated by the TGF- $\beta$ superfamily cytokine MIC-1. Nat. Med. 13, 1333-1340 (2007).

5. Bootcov, M.R. et al. MIC-1, a novel macrophage inhibitory cytokine, is a divergent member of the TGF- $\beta$ superfamily. Proc. Natl. Acad. Sci. 94, 11514-11519 (1997).

6. Böttner, M., Suter-Crazzolara, C., Schober, A. \& Unsicker, K. Expression of a novel member of the TGF-beta superfamily, growth/differentiation factor15/macrophage-inhibiting cytokine-1 (GDF-15/MIC-1) in adult rat tissues. Cell Tissue Res. 297, 103-110 (1999).

7. Unsicker, K., Spittau, B. \& Krieglstein, K. The multiple facets of the TGF- $\beta$ family cytokine growth/differentiation factor-15/macrophage inhibitory cytokine-1. Cytokine Growth Factor Rev. 24, 373-384 (2013).

8. Hsiao, E.C. et al. Characterization of growth-differentiation factor 15, a transforming growth factor beta superfamily member induced following liver injury. Mol. Cell. Biol. 20, 3742-3751 (2000).

9. Schober, A. et al. Expression of growth differentiation factor-15/ macrophage inhibitory cytokine-1 (GDF-15/MIC-1) in the perinatal, adult, and injured rat brain. J. Compar. Neurol. 439, 32-45 (2001).

10. Welsh, J.B. et al. Large-scale delineation of secreted protein biomarkers overexpressed in cancer tissue and serum. Proc. Natl. Acad. Sci. 100, 3410-3415 (2003).

11. Brown, D.A. et al. Serum macrophage inhibitory cytokine 1 in rheumatoid arthritis: a potential marker of erosive joint destruction. Arthritis Rheum. 56, 753-764 (2007).

12. Koopmann, J. etal. Serum Macrophage inhibitory cytokine 1 as a marker of pancreatic and other periampullary cancers. Am. Assoc. Cancer Res. 10, 2386-2392 (2004).

13. Wollert, K.C. et al. Prognostic value of growth-differentiation factor-15 in patients with non-ST-elevation acute coronary syndrome. Circulation 115, 962-971 (2007).

14. de Jager, S.C.A. et al. Growth differentiation factor 15 deficiency protects against atherosclerosis by attenuating CCR2-mediated macrophage chemotaxis. J. Exp. Med. 208, 217-225 (2011).
15. Kempf, T. et al. GDF-15 is an inhibitor of leukocyte integrin activation required for survival after myocardial infarction in mice. Nat. Med. 17, 581-588 (2011).

16. Celli, B.R. et al. The body-mass index, airflow obstruction, dyspnea, and exercise capacity index in chronic obstructive pulmonary disease. N. Engl. J. Med. 350, 1005-1012 (2004).

17. Freeman, C.M. et al. Acute exacerbations of chronic obstructive pulmonary disease are associated with decreased CD4 + \& CD8 + T cells and increased growth \& differentiation factor-15 (GDF-15) in peripheral blood. Respir. Res. 16, 94 (2015).

18. Mutlu, L. et al. Growth differentiation factor-15 is a novel biomarker predicting acute exacerbation of chronic obstructive pulmonary disease. Inflammation 38, 1-9 (2015).

19. Patel, M.S. et al. Growth differentiation factor 15 is associated with muscle mass in chronic obstructive pulmonary disease and promotes muscle wasting in vivo. J. Cachexia Sarcopenia Muscle 7, 436-448 (2016).

20. Nickel, N. et al. GDF-15 is abundantly expressed in plexiform lesions in patients with pulmonary arterial hypertension and affects proliferation and apoptosis of pulmonary endothelial cells. Respir. Res. 12, 62 (2011).

21. Nickel, N. et al. Growth differentiation factor-15 in idiopathic pulmonary arterial hypertension. Am. J. Respir. Crit. Care Med. 178, 534-541 (2008).

22. Lambrecht, S. et al. Growth differentiation factor 15, a marker of lung involvement in systemic sclerosis, is involved in fibrosis development but is not indispensable for fibrosis development. Arthritis Rheum. 66, 418-427 (2014).

23. Wu, Q., Jiang, D. \& Chu, H.W. Cigarette smoke induces growth differentiation factor 15 production in human lung epithelial cells: Implication in mucin over-expression. Innate Immun. 18, 617-626 (2012).

24. Wu, Q. et al. Cigarette smoke induces human airway epithelial senescence via GDF15 production. Am. J. Respir. Cell Mol. Biol. 55, 429-438 (2016).

25. Zimmers, T.A. et al. Growth differentiation factor-15/macrophage inhibitory cytokine-1 induction after kidney and lung injury. Shock 23, 543-548 (2005).

26. Bonaterra, G.A. et al. growth differentiation factor- 15 deficiency inhibits atherosclerosis progression by regulating interleukin-6-dependent inflammatory response to vascular injury. J. Am. Heart Assoc. 1, e002550 (2012).

27. Kempf, T. et al. The transforming growth factor-beta superfamily member growth-differentiation factor- 15 protects the heart from ischemia/reperfusion injury. Circ. Res. 98, 351-360 (2006).

28. Zhou, Z. et al. Growth differentiation factor- 15 suppresses maturation and function of dendritic cells and inhibits tumor-specific immune response. PLoS One 8, e78618 (2013).

29. Mazagova, M. et al. Genetic deletion of growth differentiation factor 15 augments renal damage in both type 1 and type 2 models of diabetes. Am. J. Physiol. Renal Physiol. 305, F1249-F1264 (2013).

30. Barnes, P.J. \& Celli, B.R. Systemic manifestations and comorbidities of COPD. Eur. Respir. J. 33, 1165-1185 (2009).

31. Ding, Q. et al. Identification of macrophage inhibitory cytokine-1 in adipose tissue and its secretion as an adipokine by human adipocytes. Endocrinology 150, 1688-1696 (2009).

32. Patel, M.S. et al. Growth differentiation factor- 15 is associated with muscle mass in chronic obstructive pulmonary disease and promotes muscle wasting in vivo. J. Cachexia Sarcopenia Muscle 7, 436-448 (2015).

33. Demedts, I.K. et al. Elevated MMP-12 protein levels in induced sputum from patients with COPD. Thorax 61, 196-201 (2006).

34. D'hulst, A.I., Vermaelen, K.Y., Brusselle, G.G., Joos, G.F. \& Pauwels, R.A. Time course of cigarette smoke-induced pulmonary inflammation in mice. Eur. Respir. J. 26, 204-213 (2005).

35. Bracke, K.R. et al. Cigarette smoke-induced pulmonary inflammation, but not airway remodelling, is attenuated in chemokine receptor 5-deficient mice. Clin. Exp. Allergy 37, 1467-1479 (2007).

36. Bracke, K.R. et al. Matrix metalloproteinase-12 and cathepsin D expression in pulmonary macrophages and dendritic cells of cigarette smoke-exposed mice. Int. Arch. Allergy Immunol. 138, 169-179 (2005).

37. Verhamme, F.M. et al. Role of activin-A in cigarette smoke-induced inflammation and COPD. Eur. Respir. J. 43, 1028-1041 (2014).

38. Vandesompele, J. et al. Accurate normalization of real-time quantitative RT-PCR data by geometric averaging of multiple internal control genes. Genome Biol. 3, RESEARCH0034 (2002). 